\title{
Elective cardiac retransplantation. First case in Mexico
}

\author{
Guillermo Careaga-Reyna and Hugo Jesús Zetina-Tun \\ Instituto Mexicano del Seguro Social, Centro Médico Nacional La Raza, General Hospital, Ciudad de México, Mexico
}

\begin{abstract}
Orthotopic cardiac retransplantation is used to treat transplanted cardiac graft end-stage failure. We present the first case of successful elective cardiac retransplantation in Mexico. It was a 25-year old male with heart transplantation who developed graft-resistant chronic vasculopathy. He underwent elective retransplantation in September 2017; complications during postoperative evolution were treated with favorable response. He was discharged owing to improvement at four weeks postoperatively. It is concluded that in adequately selected cases and comprehensively assessed, cardiac retransplantation is an appropriate option to treat cardiac graft failure.
\end{abstract}

KEY WORDS: Cardiac retransplantation. Chronic rejection. Immunosuppression. Chronic heart failure. Cardiac allograft vasculopathy.

\section{Introduction}

Throughout decades, heart transplantation has been shown to be the ideal option for definitive treatment of end-stage heart failure of diverse causes; with current immunosuppressive therapy, patient survival and quality of life has increased, ${ }^{1}$ although long-term mortality continues to be high due to chronic complications such as graft vasculopathy, especially at 5 years post-transplant. ${ }^{2}$

Graft vasculopathy is a condition characterized by the appearance of multiple obstructive, diffuse, eccentric coronary lesions, most times not manageable with interventional cardiology. ${ }^{3}$ Once diagnosed, different forms of treatment, such as aggressive immunosuppression, percutaneous coronary interventionism with stenting and even coronary revascularization surgery are used. However, these modalities may not be sufficient and the lesions progress and heart failure increases, with heart retransplantation being left as the only option. ${ }^{4}$

Heart retransplantation accounts for up to $3 \%$ of all heart transplants in the world, ${ }^{4}$ and is indicated to treat chronic graft vasculopathy (37\%), early graft dysfunction (32\%) and acute cardiac graft rejection (14\%). ${ }^{5,6}$ Survival is $4 \%$ lower than in the first transplant at one year and
$70 \%$ versus $80 \%$ at 3 years. ${ }^{4}$ Survival is lower if retransplantation is carried out within the first 2 years after the first transplant, ${ }^{6,7}$ especially when the interval between both transplantations is shorter than 6 months. Risk factors in retransplantation are age $>60$ years in the recipients and female gender donors. Long and medium term perioperative and postoperative complications are similar than in the first transplant, and survival of patients undergoing heart transplantation for the first time and retransplantation is similar. ${ }^{8,9}$

We present the experience with the first elective heart retransplantation carried out in Mexico.

\section{Clinical case}

Man of 25 years, who on October 20, 2009 received a bicaval orthotopic heart transplant as a national emergency for presenting end-stage resistant and irreversible heart failure, secondary to idiopathic dilated cardiomyopathy of one-year evolution, with recovery and hospital discharge at the tenth day of postoperative period. His immunosuppressive management was with steroids, mycophenolate mofetil and tacrolimus, with satisfactory clinical evolution, at functional class $\$ of the New York Heart Association (NYHA) scale until
Correspondence:

Guillermo Careaga-Reyna

E-mail: gcareaga3@gmail.com
Date of reception: 19-12-2017

Date of acceptance: 23-04-2018

DOI://dx.doi.org/10.24875/GMM.M18000198
Gac Med Mex. 2018;154:524-526

Contents available at PubMed www.gacetamedicademexico.com 
January 2016, when deterioration started until reaching NYHA functional class III and sinus bradycardia.

International Society for Heart and Lung Transplantation (ISHLT) classification 1R acute rejection was documented by histopathology, which prompted immunosuppressive treatment adjustment to therapeutic ranges. In May 2016, he experienced a syncope and the electrocardiogram showed second degree atrioventricular block, with sinus pauses, plus a left ventricular ejection fraction (LVEF) of $40 \%$ and left ventricle dilatation to $54 \mathrm{~mm}$. Unicameral pacemaker implant was decided, whereby improvement to NYHA functional class II was observed. In January 2017, he experienced periods of supraventricular tachycardia, which was treated with oral amiodarone; 3 months later, deterioration to NYHA functional class III, edema of legs, dyspnea and occasional orthopnea and tachyarrhythmias were observed, as well as $5-\mathrm{kg}$ weight loss in 6 weeks. With a new echocardiogram, LVEF of $40 \%$, left ventricle diastolic diameter of $56 \mathrm{~mm}$ and tricuspid annular plane systolic excursion (TAPSE) of $12 \mathrm{~mm}$ were recorded, with pulmonary arterial tree (PAT) 34/18 and pulmonary systolic arterial pressure (PSAP) of $19 \mathrm{mmHg}$. The Holter indicated supraventricular and ventricular tachycardia self-limiting episodes. Coronary angiography and endomyocardial biopsy were performed, which showed plurivascular disease with diffuse lesions and ISLHT classification $2 \mathrm{R}$ acute rejection. With these data, graft vasculopathy of severe degree was confirmed.

A medicated stent was placed in the descending anterior coronary artery and in May of same year, the unicameral pacemaker was replaced with an implantable automatic defibrillator. The need to perform heart retransplantation was proposed, and in preparation thereof, panel reactive antibody (PRA) levels were measured: class I, $22 \%$; class II, $77 \%$. The patient underwent antibody desensitization with $1 \mathrm{~g} / \mathrm{kg} /$ week of intravenous immunoglobulin $\mathrm{G}$, for 4 doses, followed by rituximab, $375 \mu \mathrm{g} / \mathrm{m}^{2}$ body surface.

Once desensitization was concluded and since there was a compatible donor, heart retransplantation was performed on August 18, 2017. Surgical approach was carried out in the previous sternotomy, which was found to be type III, with lysis of adhesions, placement of cardiopulmonary bypass system, heart graft removal and implant of new heart, with graft total ischemia time of 305 minutes; cardiopulmonary bypass time was 265 minutes and aortic clamping 81 minutes. Postoperatively, the patient had greater hemorrhage than usual, AKIN III acute renal failure, which required renal replacement therapy with peritoneal dialysis for 72 hours. The echocardiogram showed biventricular dysfunction, predominantly right, treated with inotropes and vasopressors. Mechanical ventilation was withdrawn on the ninth day after surgery. Owing to data consistent with nosocomial pneumonia and growth in Candida albicans culture, he received caspofungin for 14 days. The patient remained in post-surgery intensive therapy for 13 days and was discharged from the hospital 22 days after the procedure. The discharge echocardiogram showed LVEF of $65 \%$, TAPSE of $15 \mathrm{mmHg}$ and minimal pericardial effusion. For immunosuppression, $2.4 \mathrm{mg} / \mathrm{kg}$ of thymoglobulin distributed in three doses were used which were complemented with steroids, mycophenolate mofetil and sirolimus. The last sirolimus level was $4 \mathrm{nmol} / \mathrm{L}$. Endomyocardial biopsy at 45 days showed no rejection data and at the moment of this report the patient was at NYHA functional class I.

\section{Discussion}

The improvement in heart transplantation results make it the best therapeutic option for end-stage heart failure; this is due to patient selection, immunosuppression, medical-surgical groups' technical experience, organ preservation and postoperative care. ${ }^{1}$

Improvements in survival and quality of life are accompanied by the possibility of complications related to immunosuppression, such as infections and organ rejection. One of the expressions of the latter is graft vasculopathy, which occurs in $43 \%$ of angiographic studies and in up to $80 \%$ of vascular ultrasounds, mainly in children. ${ }^{10}$ Evolution of this disease is progressive and even with the use of other options, such as percutaneous coronary intervention or revascularization surgery, heart retransplantation is the only option in well selected cases. ${ }^{5,11-13}$ The first heart retransplantation was carried out by Copeland's group in $1977^{14}$ and, ever since, the performance of this procedure has increased.

Heart retransplantation accounts for between 3 and $5.4 \%$ of total heart transplants performed in the world, ${ }^{2,4}$ although it has been reported to account for up to $15 \% .^{14}$ Its main indication is graft vasculopathy, in 37 to $90.3 \%$. The other indications are acute rejection and primary dysfunction of the cardiac graft. Its indication has increased in patients aged between 0 and 17 years and in the age group of 18 to 49 years..$^{15}$

Regarding survival after retransplantation, the time between the first and the second transplant is a risk factor: 1-year survival is $65 \%$ in those in whom the interval is shorter than 2 years, compared to $75 \%$ for those in 
whom retransplantation was carried out in a longer interval. ${ }^{4}$ Tsao et al.16 demonstrated that mortality increases with prior prolonged and intense immunosuppression (which increases the risk for patients to develop malignant neoplasms), previous failure of other organs before retransplantation, older age, female gender and ischemic heart disease as the cause of the first transplant. Other cited factors are previous surgery, high levels of PRA and prolonged immunosuppressant use side effects. ${ }^{15}$ However, in the long term, if care is taken in recipient selection, Grun et al. insist on considering the period elapsed between the first transplant and retransplantation as a selection criterion. ${ }^{17}$

When comparing patients with graft vasculopathy who were medically treated with patients who were retransplanted for the same reason, better results were observed for retransplantation in patients who had systolic dysfunction; however, it is insisted on being very careful in the selection. ${ }^{18}$ In our experience, previous surgery has not been shown to be a relevant factor in the first transplantation. ${ }^{19}$

The described case is the first heart retransplantation in Mexico carried out in an elective form, the result of which was successful. We can conclude that this procedure is an appropriate option for well selected cases, after carefully analyzing risk factors and clinical conditions.

\section{References}

1. Careaga-Reyna G, Zetina-Tun H, Lezama-Urtecho CA. Programa de trasplante cardiaco de la Unidad Médica de Alta Especialidad, Hospital General Dr. Gaudencio González Garza del Centro Médico Nacional La Raza. Rev Invest Clin. 2011;63(Supl 1):85-90.

2. Topkara VK, Dang NC, Cheema JR, Barbato R, Cavallo M, Liu JF, et al. A decade experience of cardiac retransplantation in adult recipients. $J$ Heart Lung Transplant. 2005;24(11):1745-1750. DOI: 10.1016/j. healun 2005.02.015

3. Mehra MR, Crespo-Leiro MG, Dipchand A, Ensminger SM, Hiemann NE, Kobashigawa JA, et al. International Society for Heart and Lung
Transplantation working formulation of a standardized nomenclature for cardiac allograft vasculopathy-2010. J Heart Lung Transplant. 2010;29(7):717-727. DOI: 10.1016/j.healun.2010.05.017

4. Magee JC, Barr ML, Basadonna GP, Johnson MR, Mahadevan S, McBride MA, et al. Repeat organ transplantation in the United States, 1996-2005. Am J Transplant. 2007;7(5 Pt 2):1424-1433. DOI: 10.1111/j.1600-6143.2007.01786.x

5. Radovancevic B, McGiffin DC, Kobashigawa JA, Cintron GB, Mullen GM, Pitts DE, et al. Retransplantation in 7,290 primary transplant patients: a 10-year multiinstitutional study. J Heart Lung Transplant. 2003;22:862868. DOI: 10.1016/S1053-2498(02)00803-3

6. Pozzi C, d'Alessandro C, Fernandez F, Nguyen A, Pavie A, Leprince $P$, et al Who gets a second heart? A current picture of cardiac retransplantation. Transplant Proc 2014; 46; 202-207. DOI: 10.1016/j.transproceed.2013.08.109

7. Srivastava R, Keck BM, Bennett LE, Hosenpud JD. The results of cardiac retransplantation: an analysis of the Joint International Society for Heart and Lung Transplantation/United Network for Organ Sharing Thoracic Registry. Transplantation. 2000;70(4):606-612.

8. Johnson MR, Aaronson KD, Canter CE, Kirklin JK, Mancini DM, Mehra MR et al. Heart retransplantation. Am J Transplant. 2007;7(9):2075-2081. DOI: $10.1111 / \mathrm{j} .1600-6143.2007 .01902 . x$

9. Saito A, Novick RJ, Kiaii B, McKenzie FN, Quantz M, Pflugfelder P, et al. Early and late outcomes after cardiac retransplantation. Can J Surg. 2013;56(1):21-26. DOI: 10.1503/cjs.012511

10. Doshi AA, Rogers J, Kern MJ, Hauptman PJ. Effectiveness of percutaneous coronary intervention in cardiac allograft vasculopathy. Am J Cardiol. 2004;93(1):90-92. DOI: 10.1016/j.amjcard.2003.08.075

11. Taylor DO, Edwards LB, Mohacsi PJ, Boucek MM, Trulock EP, Keck BM, et al. The Registry of the International Society for Heart and Lung Transplantation: twentieth official adult heart transplant report-2003, J Heart Lung Transplant. 2003;22(6):616-624.

12. Patel VS, Radovancevic B, Springer W, Frazier OH, Massin E, Benrey J, et al. Revascularization procedures in patients with transplant coronary artery disease. Eur J Cardiothorac Surg. 1997;11(5): 895-901.

13. Tham EB, Yeung AC, Cheng CW, Bernstein D, Chin C, Feinstein JA. Experience of percutaneous coronary intervention in the management of pediatric cardiac allograft vasculopathy. J Heart Lung Transplant. 2005;24(6):769-773. DOI: 10.1016/j.healun.2004.04.009

14. Copeland JG, Griepp RB, Bieber CP, Billingham M, Schroeder JS Hunt S, et al. Successful retransplantation of the human heart. J Thorac Cardiovasc Surg. 1977;73(2):242-247.

15. Tjang YS, Tenderich G, Hornik L, Körfer R. Cardiac retransplantation in adults: an evidence-based systematic review. Thorac Cardiovasc Surg. 2008;56(6):323-327. DOI: 10.1055/s-2008-1038662

16. Tsao L, Uriel N, Leitz K, Naka Y, Mancini D. Higher rate of comorbidities after cardiac retransplantation contributes to decreased survival. J Heart Lung Transplant. 2009;28(10):1072-1074. DOI: 10.1016/j.healun.2009.06.004

17. Grun S, Ceruti B, Chiesa P, Díaz P, Manfredi A, Leone R. Retrasplante cardíaco: a propósito del primer caso en Uruguay. Rev Urug Cardiol. 2006;21(2):124-130. http://www.scielo.edu.uy/scielo.php?script=sci_arttext\&pid=S1688-04202006000200004

18. Goldraich LA, Stehlik J, Kucheryavayya AY, Edwards LB, Ross HJ. Retransplant and medical therapy for cardiac allograft vasculopathy: International Society for Heart and Lung Transplantation Registry Analysis. Am J Transplant. 2016;16:301-309. DOI: 10.1111/ajt.13418

19. Careaga-Reyna G, Zetina-Tun HJ, Lezama-Urtecho CA, Arellano-Juárez L, Alvarez-Sánchez LM. Trasplante de corazón en pacientes con cirugía cardiaca previa. Cir Cardiov. 2017;24(1):22-25. DOI:10.1016/j. circv.2016.09.010 